\title{
SUSTENTABILIDADE AMBIENTAL: ANÁLISE DE UMA EMPRESA DE "BLOCOS VERDES PRÉ-FABRICADOS" PARA UTILIZAÇÃO EM UNIVERSIDADES PÚBLICAS FEDERAIS.
}

\section{ENVIRONMENTAL SUSTAINABILITY: ANALYSIS OF A COMPANY \\ "CANNED GREEN BLOCKS" FOR USE IN FEDERAL PUBLIC UNIVERSITIES.}

\author{
Morgana Mendes Nunes ${ }^{1}$; Elisete Dahmer Pfitscher ${ }^{2}$ \\ ${ }^{1}$ Universidade Federal de Santa Catarina - UFSC - Santa Catarina - Brasil \\ morgana_pl@hotmail.com \\ ${ }^{2}$ Universidade Federal de Santa Catarina - UFSC - Santa Catarina - Brasil \\ elisete.dahmer@ufsc.br
}

\begin{abstract}
Resumo
Este estudo tem por objetivo verificar a sustentabilidade e gestão ambiental de uma empresa de blocos verdes pré-fabricados, localizada no município da grande Florianópolis, para a utilização em Universidades Públicas Federais. Para atender a esse objetivo têm-se os seguintes objetivos especificos verificar a existência de resíduos de cascas de ostras e mariscos para a fabricação dos blocos; analisar a sustentabilidade parcial por critérios na empresa estudada e propor um modelo resumido de gestão ambiental $5 \mathrm{~W} 2 \mathrm{H}$. A metodologia utilizada foi de carácter descritivo e exploratório; quanto aos procedimentos técnicos considera-se estudo de caso "in loco" $e$ documental. Através da lista de verificação pode-se observar que a sustentabilidade global é de 82\% considerando adequado. Já o critério 5 - Contabilidade a Auditoria Ambiental destacou-se como o mais deficitário, com um índice de sustentabilidade de 66,67\% classificado como regular. Por não haver um empenho da empresa relacionado com a proteção, controle e recuperação ambiental, apesar de ter um avanço tecnológico na utilização de resíduos da maricultura para a fabricação de blocos e pavimentos ecológicos. Quanto à utilização dos Blocos em Universidades Públicas Federais, não foi constatado sua presença, porém são as responsáveis pelo incentivo ao desenvolvimento sustentável, já que tem a função de formar cidadãos capacitados para o desenvolvimento socioambiental.
\end{abstract}

Palavras-chave: sustentabilidade ambiental; empresa de blocos verdes pré-fabricados; universidades públicas federais.

\section{Introdução}

A crescente preocupação com degradação do meio ambiente não é mais apenas de ambientalistas, agora passa a ser de empresários que usufruem desses recursos para seu desenvolvimento econômico e material e também de Instituições de Ensino Superior que tem a função de incentivar os discentes a pesquisas e práticas sustentáveis. 
Gestão ambiental auxilia a sustentabilidade, através de métodos utilizados para diminuir os impactos causados ao meio ambiente, a aderência deste a empresa pode auxiliar na redução de custos através da reutilização de seus próprios resíduos. Na visão de Andreoli (2009), a gestão ambiental auxilia os empresários a realizarem melhorias quanto às atividades que causam impactos ao meio ambiente $\mathrm{e}$ as atividades financeiras.

Segundo Tauchen e Brandli (2006) os gestores das Instituições de Ensino Superior (IES) estão preocupados com a questão da sustentabilidade, pois prepara os cidadãos tomadores de decisão do amanhã, porém ainda são poucas as práticas observadas nas Universidades Públicas Federais.

Assim, a problemática desta pesquisa fica resumida na seguinte questão problema: como se encontra a sustentabilidade ambiental de uma empresa de "blocos verdes pré-fabricados" com a incorporação de conchas de ostras e mariscos para utilização em Universidades Públicas Federais?

Nesta perspectiva, o objetivo geral deste estudo é verificar a sustentabilidade e gestão ambiental de uma empresa de blocos verdes pré-fabricados, localizada no munícipio da grande Florianópolis, para a utilização em Universidades Públicas Federais. Neste sentido para atender ao objetivo geral têm-se os seguintes objetivos específicos, verificar a existência de resíduos de cascas de ostras e mariscos para a fabricação dos blocos, também analisar a sustentabilidade parcial por critérios na empresa estudada e propor um modelo resumido de gestão ambiental 5W2H.

\section{Revisão teórica}

\subsection{Responsabilidade social \& sustentabilidade}

A Responsabilidade Social hoje é um ponto crucial dentro das mais variadas entidades. As empresas estão se preocupando para entender e compreender este termo, para possam atribuir a sua empresa. Da mesma forma as Instituições de Ensino de Superior que são grandes propulsoras de conhecimento e formação de profissionais, não deve preocupar-se apenas com teorias, mas também com práticas socioambientais.

Conforme Souza et al (2007) a "Responsabilidade Social, no seu sentido amplo, aborda questões relativas aos deveres de cada indivíduo e organização com o bem-estar da sociedade, enfatizando que todos devem preocupar-se em assumir seus atos, já no sentido restrito podem ser direcionadas especificamente às organizações, denominada como Responsabilidade Social Empresarial, que é adaptada às capacidades e limitações das empresas”.

Segundo TACHIZAWA (2004, p. 73):

A responsabilidade social e ambiental pode ser resumida no conceito de "efetividade", como o alcance de objetivos do desenvolvimento econômico-social. Portanto, uma organização é efetiva quando mantém uma postura socialmente responsável. 
Responsabilidade Ambiental são atitudes da sociedade no geral, para com o meio ambiente, ou seja, atitudes que podem levar ao desenvolvimento sustentável que garante proteção e controle ambiental. A partir deste pressuposto, a empresa estudada adota a Responsabilidade Ambiental e desenvolve ações que promovem melhorias nas construções civis através dos blocos verdes feitos com conchas de ostras e mariscos.

A Responsabilidade Ambiental, segundo Luiz et al (2011, p. 55) “está implícita no contexto de Responsabilidade Social, pois agir com responsabilidade junto ao meio ambiente é ter a certeza de que tudo o que dele for retirado não supera sua capacidade de renovação, e tudo o que nele for depositado não vai prejudicá-lo".

Atualmente a Responsabilidade Ambiental vem tendo aceitação e permite uma consciência ambiental a todos os stakeholders nas organizações, fazendo com que as mesmas atendam as necessidades de mercado, sem impactar o meio ambiente.

Conforme Cardoso e Pfitscher (2011), responsabilidade ambiental é um compromisso com a sociedade, pois deve decidir reflexos causados a estes sobre as decisões tomadas, com o intuito de evitar danos causados ao meio ambiente e ao seu entorno, seguindo os padrões das normas ambientais.

Desenvolvimento sustentável remete a um modelo econômico, social e ambiental, que segue parâmetros para não comprometer a sociedade no geral, tendo em vista a preservação dos recursos naturais.

O conceito de sustentabilidade, segundo Drunn et al (2011) é baseado na economia, na cultura, na politica e preocupação socioambiental, pois todos esses temas tem diferentes preocupações, mas o objetivo final são iguais.

Freitas et al (2012) acredita que "a partir dos relatos contidos nos trabalhos científicos a sustentabilidade das instituições de ensino superior, torna-se importante, pois a formação de opinião nas universidades, se dá a partir da literatura científica".

O termo Sustentabilidade segundo Claro (2008) deve satisfazer a necessidade das gerações presentes, sem prejudicar as necessidades das futuras gerações, é dividida em três ações relacionadas entre si: econômica, social e ambiental.

\subsection{Gestão ambiental}

Gestão ambiental utiliza métodos que garantem a preservação do ecossistema, a reutilização de resíduos e a diminuição dos impactos ambientais. A empresa em estudo introduz métodos em seu planejamento empresarial, para a redução dos custos através da utilização de resíduos de matériasprimas e de recursos escassos como a água e a energia. 
Vargas et al (2010) conceitua gestão ambiental, como um conjunto de políticas, programas e práticas administrativas e operacionais desenvolvidas pelas entidades, pois leva em conta a saúde e a segurança das pessoas e também a proteção do meio ambiente através da redução ou extinção dos impactos e danos ambientais.

Neste sentido, Tinoco e Robles (2006) conceituam Gestão Ambiental como um sistema que inclui a estrutura organizacional. Planejamentos, responsabilidades, práticas, procedimentos e recursos para desenvolver, implantar, atingir, analisar criticamente e manter a política ambiental. Isso é o que a empresa faz para minimizar ou eliminar os efeitos negativos provocados no ambiente pelas suas atividades. Logo para que uma empresa tenha uma gestão ambiental correta deve mudar sua cultura organizacional, já que essa gestão tem sido considerada uma das atividades mais importantes dentro das entidades.

\subsection{Sistema de gestão ambiental}

Nesta etapa, são apresentadas brevemente os sistemas de gestão ambiental, "GAIA" e "SICOGEA", bem como suas respectivas fases. Cabe ressaltar que para este estudo foi utilizado a primeira fase da terceira etapa do SICOGEA e a terceira fase - Capacitação e Qualificação - do método GAIA, que propõe um plano de gestão ambiental.

\subsubsection{Gerenciamento de aspectos e impactos ambientais - GAIA}

O método GAIA foi desenvolvido na tese doutorado do Professor Alexandre de Ávila Lerípio. Segundo Lerípio (2001), este método foi dividido em três fases como mostra na Figura 1 e tem a função de auxiliar as organizações na evidenciação de problemas ambientais que possam estar acontecendo dentro da empresa e propor soluções de melhorias.

Segundo Pfitscher (2009, p.75-80) explica que a primeira fase é dividida em três atividades: sustentabilidade do negócio, estratégia ambiental e comprometimento e sensibilização das partes interessadas. Na segunda fase se faz o mapeamento da cadeia de produção e consumo, mapeamento do macro fluxo do processo e estudo de entradas e saídas dos processos e inventário de aspectos e impactos ambientais e na terceira e última fase são apresentadas as ações de identificação de oportunidade de melhoria, estudo da viabilidade técnica, econômica e ambiental e o planejamento.

$\mathrm{Na}$ visão de Pfitscher (2004, p. 81), “O GAIA surgiu para valorizar as empresas, as organizações e as áreas de recursos humanos nelas inseridas. Valoriza também o público consumidor, uma vez que, ao verificar o impacto ambiental, atua na sociedade".

Portanto, o método GAIA foi criado para mostrar aos gestores o quanto cada setor da empresa pode prejudicar o meio ambiente e a sociedade a seu redor, sensibilizando e conscientizando sobre o impacto ambiental encontrado em cada departamento, além de propor melhorias sustentáveis. 


\subsubsection{Sistema contábil gerencial ambiental - SICOGEA}

O Sistema Contábil Gerencial Ambiental - SICOGEA foi desenvolvido na tese de doutorado da Professora Elisete Dahmer Pfitscher, com a finalidade de gerenciar os aspectos e impactos ambientais com a utilização da Contabilidade e Controladoria Ambiental. Sua aplicação divide-se em três etapas: integração da cadeia produtiva; gestão do controle ecológico e gestão da contabilidade e controladoria ambiental. Isto porque a primeira aplicação foi em uma Cadeia produtiva de arroz ecológico.

De acordo com Pamplona et al (2011), o SICOGEA é um instrumento de gestão ambiental que integra a contabilidade ao meio ambiente, sua principal função é informar os impactos causados ao meio ambiente e aos controladores das entidades.

Segundo Pfitscher (2004, p. 118) a gestão das empresas rurais e as beneficiadoras (ciclo produtivo) necessitam de controles que muitas vezes nem existem. Por isso a aplicação da terceira etapa do método, que é a gestão da contabilidade e controladoria ambiental dividida em três fases.

Limongi, Soares e Freitas (2013, p.19), sintetizam as três etapas do SICOGEA, na "primeira etapa tinha como missão o envolvimento da cadeia produtiva, ou seja, mostrar as degradações causadas em cada atividade e sua situação econômica, quanto à segunda etapa tinha como objetivo evitar esforços, a fim de reduzir ou eliminar impactos ambientais e na terceira e última fase mostrava o desfecho com a implantação de novas alternativas para continuidade".

Para este estudo, é necessário ressaltar que foi utilizado para a análise dos resultados, apenas a primeira fase da terceira etapa do SICOGEA, explicado no Quadro 1, que é a "Gestão da contabilidade e controladoria ambiental", ou seja, apresentam-se as fases de investigação e mensuração; informação e as decisões a serem tomadas.

Quadro 1 - Terceira etapa do SICOGEA

\begin{tabular}{|c|c|c|}
\hline Fases da terceira etapa & Descrição & Observações \\
\hline Investigação e mensuração & $\begin{array}{c}\text { Sustentabilidade e estratégia; sensibilização das partes } \\
\text { interessadas e comprometimento }\end{array}$ & Análise prévia da empresa \\
\hline Informação & $\begin{array}{l}\text { Mapeamento da cadeia de produção e consumo; estudo } \\
\text { de entradas e saídas do processo; e inventário de } \\
\text { aspectos e impactos ambientais }\end{array}$ & $\begin{array}{l}\text { Estudo detalhado do ciclo } \\
\text { de produção }\end{array}$ \\
\hline Decisão & $\begin{array}{l}\text { Oportunidades de melhoria; estudo de viabilidade e } \\
\text { planejamento }\end{array}$ & $\begin{array}{l}\text { Processo de melhoria } \\
\text { continua }\end{array}$ \\
\hline
\end{tabular}

Fonte: Adaptado de Pfitscher (2004)

Na primeira fase - Investigação e mensuração - foi adaptada uma lista de verificação para a empresa de "blocos verdes pré-fabricados", aplicada in loco nos setores da empresa, separadas em critério e subcritério. A segunda fase - Informação - é composta pelo processo produtivo dos blocos, desde a entrada da matéria-prima na empresa até o produto pronto pra distribuição, tem-se então o mapeamento do processo produtivo. Quanto a terceira e última fase - Decisão - que pode ser apresentado aos gestores oportunidades de melhorias contínuas através de um planejamento, ou 
seja, um plano resumido de gestão ambiental, pois assim, podem ficar cientes da necessidade de melhorias socioambiental.

\section{Metodologia}

A metodologia empregada neste estudo foi à descritiva e exploratória. Segundo Gil (2002) a pesquisa descritiva objetiva-se na descrição de fatos e ocasiões através de questionários e observações sistemáticas que seguem um padrão de coleta de dados, e a pesquisa exploratória proporciona uma maior afinidade com a problemática tornando-a mais explicita, tendo como foco principal descobrir e aprimorar ideias e intuições.

Quanto aos procedimentos técnicos considera-se estudo de caso "in loco", que se deu através de uma entrevista semiestruturada com a engenheira ambiental da empresa, uma análise bibliográfica através de fontes secundária e documental fornecidas pela empresa estudada.

A problemática levantada neste estudo foi quali e quantitativa, conforme Moresi (2003) a pesquisa qualitativa não serve para coletar dados quantificáveis, pois é uma pesquisa mais formal, não envolve dados estatísticos, já à pesquisa quantitativa é obtida através de questionários, ou seja, não é apenas uma descrição formal dos métodos e técnicas a serem utilizados, devem discriminar as ações e medidas necessárias para o desenvolvimento do projeto.

A trajetória metodológica foi dividida em três etapas: a primeira tratou-se de uma revisão teórica onde foram estudados os temas: Responsabilidade Social e Sustentabilidade; Gestão Ambiental e; Sistemas de Gestão Ambiental: GAIA - Gerenciamento de Aspectos e Impactos Ambientais; e SICOGEA - Sistema Contábil Gerencial Ambiental.

$\mathrm{Na}$ segunda etapa foi feita uma análise dos dados, a partir de um método exploratório, que teve início com um breve histórico juntamente com informações sobre a empresa, e a coleta dos dados por meio de uma entrevista semiestruturada, com a aplicação de uma lista de verificação pertencente à primeira fase da terceira etapa do SICOGEA, contendo 50 questões divididas em cinco critérios. A entrevista foi direcionada a proprietária e Engenheira Ambiental da empresa. A seguir foi apresentado o mapeamento de produção dos "blocos verdes" para construção civil com a incorporação das cascas de ostras e mariscos.

Quanto a terceira e última etapa, por meio dos resultados obtidos na lista de verificação, têm-se a aplicação do Plano Resumido de Gestão Ambiental - 5W2H, no critério mais deficitário, para que os gestores possam reaver o problema e soluciona-los, bem como sua utilização em Universidades Públicas Federais.

\section{Análise dos resultados}

\subsection{Breve histórico da empresa pesquisada e de universidades públicas federais}


A empresa de "blocos verdes pré-fabricados" é de capital 100\% nacional, voltada para o desenvolvimento de processos de industrialização construtiva, tendo como base a alvenaria estrutural com blocos de concreto de alto desempenho. Os produtos seguem as normas ditadas pela Associação Brasileira de Normas Técnicas (ABNT) e são testados regularmente e aprovados por diversas instituições independentes, como universidades, escolas técnicas e laboratórios privados. O projeto Bloco Verde teve início em maio de 2005, este por sua vez, propõe a substituição de parte do cimento e da areia utilizados na produção do bloco por conchas de ostras e mariscos resíduos da maricultura, evitando que sejam depositados em restingas e de volta ao mar e nas orlas marinhas.

As Instituições de Ensino Superior no Brasil, segundo Santos e Cerqueira (2009) teve início em 1808 com a transferência da Corte para a Colônia. Depois foi fundada a Academia Real Militar, transformada mais tarde na Escola Central e depois em Escola Politécnica, até chegar à Escola Nacional de Engenharia da Universidade Federal do Rio de Janeiro.

Conforme Freitas et al (2011) foi a partir de1968, com a reforma universitária que se surgiu a expansão dos cursos de graduação e criação de cursos de pós-graduação e pesquisas.

Segundo Freitas (2013) as Instituições Ensino Superior (IES) como organizações, deve aplicar e praticar os conceitos de sustentabilidade, bem como o desenvolvimento sustentável, pois ela é a responsável pela formação cidadã, politica e cultural de seus discentes, oferecendo a sociedade, profissionais capacitados para o desenvolvimento social, econômico, cultural e também ambiental.

Freiras (2013) ao observar que as Universidades Públicas Federais, também causam impactos ambientais decorrentes de suas atividades, surgiram à necessidade de avaliar a sustentabilidade socioambiental em Instituições Públicas Federais de Ensino Superior, com o auxílio de um sistema gerencial de avaliação e evidenciação sócio ambiental.

Assim, diante do breve histórico da empresa analisada e de Universidades Públicas Federais, os sistemas de gestão devem ser bem estruturados, de forma a permitir que os objetivos tanto das empresas quanto das instituições sejam alcançados.

\subsection{Investigação e mensuração}

Na primeira fase da terceira etapa do SICOGEA - investigação e mensuração - pretende-se trabalhar a sustentabilidade e estratégias ambientais, o comprometimento e a sensibilização das partes interessadas, essas ações conforme Pfitscher, (2009) estão apresentadas a seguir.

a) Primeira ação: Sustentabilidade e estratégia ambiental - essa ação busca conhecer o nível de sustentabilidade. Sendo obtidos os dados através de uma lista de verificação, composta por critérios e subcritérios, aplicada aos responsáveis pela empresa. "Tendo suas respostas quantificadas em "Adequada" ou Deficitárias". Após, faz-se o calculo da sustentabilidade, obtendo o resultado sobre os critérios; 
b) Segunda ação: Comprometimento - após a obtenção dos índices de sustentabilidade em cada setor da empresa, os gestores tem a capacidade de realizar as melhorias necessárias, evitando danos ambientais. Podendo decidir a missão, visão, politica e objetivos;

c) Terceira ação: Sensibilização das partes interessadas - devem-se realizar visitas informativas na empresa, sobre agrupamentos de responsabilidades, visando à sensibilização dos envolvidos nas atividades da empresa.

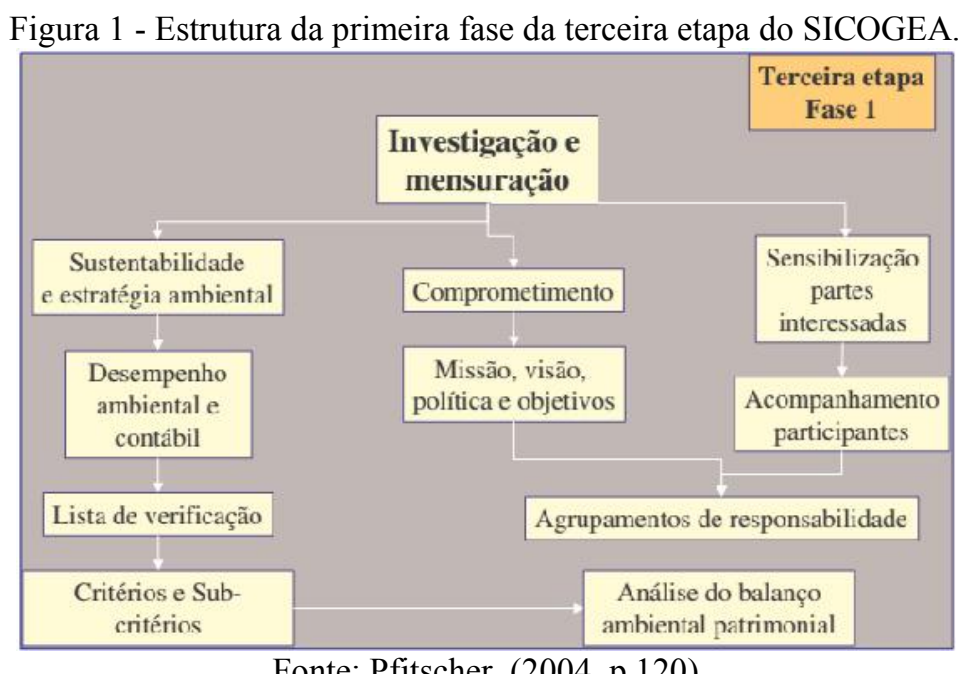

Neste estudo apresenta-se a Sustentabilidade e estratégia ambiental, através do Desempenho ambiental e Contábil, obtido com a lista de verificação que serve para analisar o índice de sustentabilidade ambiental de uma empresa específica, contudo, para que isto aconteça o pesquisador deverá conhecer os processos que a mesma utiliza. Neste sentido esta pesquisadora realiza in loco o estudo para conhecer o macro e micro-processo de produção.

O estudo de caso aplicado na empresa de blocos verdes pré-fabricados foi obtido com análise de critérios em uma lista de verificação do SICOGEA adaptado ao tipo de atividade da empresa, composta de 50 questões e divididas nestes cinco critérios, sendo que para cada questão, existiam as seguintes alternativas: Sim, Não e Não se adapta. A pesquisadora, após obtenção das respostas realiza a continuidade do estudo observando, as respostas determinadas pelas letras "A" Adequadas, "D" - Deficitárias e "NA" - Não se aplica à empresa. Vale ressaltar que a lista de verificação, ou seja, o cheklist foi preenchido pela engenheira ambiental da empresa, e as questões ficaram divididas, conforme mostra o Quadro 2: 
Quadro 2 - Critérios apontados lista de verificação

\begin{tabular}{|c|c|c|}
\hline Ordem & Ordem critério & No. Questões \\
\hline 1 & Fornecedores & 5 \\
\hline 2 & Execução do serviço & 8 \\
\hline 3 & Responsabilidade socioambiental & 7 \\
\hline 4 & Disponibilidade de capital & 18 \\
\hline 5 & Contabilidade a auditoria ambiental & 50 \\
\hline
\end{tabular}

Fonte: adaptado de Lerípio (2001) e Pfitscher, (2004)

A sustentabilidade dos critérios é verificada através de uma fórmula que gera o resultado em porcentagem, esses valores classificam a empresa em deficitária, adequada ou regular, a fórmula aplicada é apresentada na Figura 2:

Figura 2 - Fórmula sustentabilidade

$$
\text { sustentaburdade }=\frac{\text { Quadros "A" (adequado) } \times 100}{\text { Total de questões }- \text { Quadros "NA" }}
$$

Fonte: Pfitscher (2004)

Após a obtenção do resultado de sustentabilidade com a aplicação da fórmula, prosseguiu-se a análise do nível de sustentabilidade da empresa, tendo como base os parâmetros apresentados na Tabela 1.

Tabela 1 - Grau de Sustentabilidade Ambiental

\begin{tabular}{c|c|c}
\hline RESULTADO & SUSTENTABILIDADE & $\begin{array}{c}\text { DESEMPENHO: CONTROLE, INCENTIVO, ESTRATÉGIA } \\
\text { COMPETITIVA. }\end{array}$ \\
\hline Inferior a $50 \%$ & Deficitário - "D" & Fraco, pode estar causando danos ao meio ambiente \\
\hline Entre 51 e $70 \%$ & Regular - "R" & Médio, atende somente à legislação \\
\hline Mais de $71 \%$ & Adequado - "A" & $\begin{array}{c}\text { Alto, valorização ambiental com produção ecológica e prevenção da } \\
\text { Poluição }\end{array}$ \\
\hline
\end{tabular}
Fonte: Lerípio (2001), Miranda e Silva (2001 apud PFITSCHER, 2014, p.130)

Depois de informado os critérios da lista e a formula do Grau de Sustentabilidade, analisa-se sustentabilidade global, bem como cada critério individualmente para saber qual é o mais deficitário e assim poder fazer um quadro de sugestões de melhoria contínua.

\subsubsection{Análise global da empresa estudada}

Análise global refere-se ao desempenho total da empresa com base em todos os critérios estabelecidos na lista de verificação, do total de questões aplicadas obteve-se 41 questões "A" adequadas, nove questões " $\mathrm{D}$ " - deficitárias e não foram apresentadas questões que "NA" não se adapta. $\mathrm{O}$ resultado apresentado da análise global foi de $82 \%$, pode-se considerar um desempenho adequado, com uma alta valorização ambiental. 


\subsubsection{Análise resultado do critério fornecedor}

Os resultados obtidos no critério fornecedores foram de 83,33\% classificando-a como "A" adequada, mas poderia aumentar seu índice através da escolha de fornecedores emergentes, para que possa quebrar o monopólio das grandes empresas no mercado.

Quadro 3 - Fornecedores

\begin{tabular}{|c|c|c|c|c|}
\hline $\mathbf{X X}$ & CRITÉRIO I - FORNECEDORES & SIM & NÃO & $\begin{array}{l}\text { NÃO SE } \\
\text { ADAPTA }\end{array}$ \\
\hline 1 & $\begin{array}{l}\text { A empresa informa a seus fornecedores suas metas, valores e código de } \\
\text { conduta? }\end{array}$ & A & & \\
\hline 2 & Os fornecedores apresentam preocupação com o meio ambiente? & A & & \\
\hline 3 & $\begin{array}{l}\text { Os fornecedores apresentam projetos impactantes ao meio ambiente e aos } \\
\text { seres humanos? }\end{array}$ & A & & \\
\hline 4 & Os fornecedores são monopolistas no mercado? & $\mathrm{D}$ & & \\
\hline 5 & Os fornecedores se obrigam a reciclar seus resíduos? & A & & \\
\hline 6 & Os fornecedores possuem alguma certificação ambiental? & A & & \\
\hline 7 & $\begin{array}{l}\text { O controle da coleta de resíduos segue normas precisas quanto ao meio } \\
\text { ambiente? }\end{array}$ & A & & \\
\hline 8 & $\begin{array}{l}\text { O armazenamento de resíduos segue normas precisas quanto ao meio } \\
\text { ambiente? }\end{array}$ & A & & \\
\hline 9 & A fabricação das peças utiliza recursos não renováveis? & $\mathrm{D}$ & & \\
\hline 10 & $\begin{array}{l}\text { As normas de segurança e meio ambiente são rigorosamente respeitadas pelos } \\
\text { funcionários? }\end{array}$ & A & & \\
\hline 11 & $\begin{array}{l}\text { A administração se mostra efetivamente comprometida com a gestão } \\
\text { ambiental? }\end{array}$ & A & & \\
\hline 12 & A mão de obra empregada é especializada, também na parte ambiental? & A & & \\
\hline
\end{tabular}

Fonte: Dados da pesquisa e adaptado de Silva (2008).

Outra questão deficitária é a utilização de fontes não renováveis na fabricação dos blocos, neste caso a água, que dá liga na mistura. O resultado encontrado através da formula de sustentabilidade: $10 \times 100 / 12=83,33 \%$.

\subsubsection{Análise resultado da execução dos serviços}

Quadro 4 - Execução do serviço

\begin{tabular}{|c|c|c|c|c|}
\hline $\mathbf{X x}$ & CRITÉRIO II - EXECUÇÃO DO SERVIÇO & SIM & NÃO & $\begin{array}{l}\text { NÃO SE } \\
\text { ADAPTA } \\
\end{array}$ \\
\hline 13 & A prestação de serviços situa-se em um mercado de alta concorrência? & A & & \\
\hline 14 & $\begin{array}{l}\text { A empresa assume a responsabilidade pela reciclagem dos seus produtos } \\
\text { usados? }\end{array}$ & A & & \\
\hline 15 & A empresa possui um sistema de tratamento dos seus resíduos internos? & A & & \\
\hline 16 & A empresa reutiliza seus resíduos? & A & & \\
\hline 17 & $\begin{array}{l}\text { A empresa procura conscientizar seus clientes sobre a preservação do meio } \\
\text { ambiente? }\end{array}$ & A & & \\
\hline
\end{tabular}

Fonte: Dados da pesquisa e adaptado de Silva (2008) 
Através da análise de execução dos serviços o índice de sustentabilidade foi de $100 \%$, ou seja, a empresa é totalmente sustentável neste critério, tem alta valorização ambiental com a produção e a preservação da poluição.

\subsubsection{Análise resultado da responsabilidade socioambiental}

Quadro 5 - Responsabilidade socioambiental

\begin{tabular}{|c|c|c|c|c|}
\hline $\mathbf{X x}$ & CRITÉRIO III - RESPONSABILIDADE SOCIOAMBIENTAL & SIM & NÃO & $\begin{array}{l}\text { NÃO SE } \\
\text { ADAPTA }\end{array}$ \\
\hline 18 & A empresa possui coleta seletiva de lixo? & 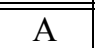 & & \\
\hline 19 & A empresa utiliza material reciclado no seu escritório? & A & & \\
\hline 20 & A empresa desenvolve conscientização ambiental para seu público interno e externo? & A & & \\
\hline 21 & $\begin{array}{l}\text { A empresa já obteve benefícios e/ou premiações pela atuação na valorização do meio } \\
\text { ambiente ou projetos sociais? }\end{array}$ & A & & \\
\hline 22 & $\begin{array}{l}\text { A empresa possui gastos com pesquisas e desenvolvimentos de projetos sociais e/ou } \\
\text { ambientais? }\end{array}$ & A & & \\
\hline 23 & A empresa possui multa e indenizações sócio- ambientais? & & A & \\
\hline 24 & A empresa apoia projetos sociais/ambientais? & A & & \\
\hline 25 & A empresa realiza pesquisas para conhecer a satisfação dos seus clientes? & A & & \\
\hline
\end{tabular}

Fonte: Dados da pesquisa e adaptado de Silva (2008)

Neste critério foi apurada uma sustentabilidade de $100 \%$, pois todas as respostas são adequadas, demonstrando que a empresa estudada tem responsabilidade socioambiental e trabalha para que isto passe a diante.

\subsubsection{Análise resultado da disponibilidade de capital}

Percebe-se neste critério apenas um item que consta deficitário pelo motivo de a empresa pagar multas e indenizações por falhas operacionais, como infração a legislação ou direito de terceiros e por isso apresenta uma sustentabilidade de $85,71 \%$, mas mantendo-a como adequada.

Quadro 6 - Disponibilidade de capital

\begin{tabular}{|c|c|c|c|c|}
\hline $\mathbf{X x}$ & CRITÉRIO IV - DISPONIBILIDADE DE CAPITAL & SIM & NÃO & $\begin{array}{l}\text { NÃO SE } \\
\text { ADAPTA }\end{array}$ \\
\hline 26 & $\begin{array}{l}\text { Existe capital próprio disponível para investimentos em gestão sócio- } \\
\text { ambiental? }\end{array}$ & A & & \\
\hline 27 & $\begin{array}{l}\text { A empresa possui bens em uso no processo de proteção, controle, preservação } \\
\text { e recuperação ambiental? }\end{array}$ & A & & \\
\hline 28 & $\begin{array}{l}\text { A empresa paga multas e indenizações por falhas operacionais, como infração } \\
\text { a legislação ou direito de terceiros? }\end{array}$ & $\mathrm{D}$ & & \\
\hline 29 & $\begin{array}{l}\text { A empresa paga multas e indenizações por acidentes ambientais, perdas por } \\
\text { exposição de pessoas e bens à poluição? }\end{array}$ & & A & \\
\hline 30 & $\begin{array}{l}\text { A empresa é ré em alguma ação judicial referente à poluição ambiental, } \\
\text { acidentes ambientais e/ou indenizações trabalhistas? }\end{array}$ & & A & \\
\hline 31 & Existe aplicação financeira em projetos ambientais? & A & & \\
\hline 32 & $\begin{array}{l}\text { A empresa acredita numa vantagem competitiva no mercado com a valorização } \\
\text { da questão ambiental? }\end{array}$ & A & & \\
\hline
\end{tabular}

Fonte: Dados da pesquisa e adaptado de Silva (2008) 
Apesar de a empresa apresentar um item deficitário, observa-se analisando as respostas que a mesma é empenhada em proteger o meio ambiente e o valoriza, investindo parte do seu capital em projetos ambientais.

\subsubsection{Análise resultado da contabilidade a auditoria ambiental}

Contabilidade a auditoria ambiental foi o critério que mais apresentou questões deficitárias com um índice de sustentabilidade de $66,67 \%$, tornando o critério V regular sob a análise realizada.

Quadro 7 - Contabilidade a auditoria ambiental

\begin{tabular}{|c|c|c|c|c|}
\hline $\mathbf{X x}$ & CRITÉRIO V - CONTABILIDADE A AUDITORIA AMBIENTAL & SIM & NÃO & $\begin{array}{l}\text { NÃO SE } \\
\text { ADAPTA }\end{array}$ \\
\hline & Ativo Circulante & & & \\
\hline 33 & A empresa possui títulos a receber? & A & & \\
\hline \multirow[t]{2}{*}{34} & A empresa possui outros créditos a receber? & A & & \\
\hline & Ativo Realizável a Longo Prazo & & & \\
\hline 35 & A empresa possui títulos a receber? & A & & \\
\hline 36 & A empresa possui outros créditos a receber? & A & & \\
\hline 37 & $\begin{array}{l}\text { A empresa possui bens em uso no processo de proteção, controle, preservação } \\
\text { e recuperação ambiental? }\end{array}$ & & $\mathrm{D}$ & \\
\hline 38 & $\begin{array}{l}\text { A empresa possui gastos com pesquisas e desenvolvimento de tecnologias } \\
\text { ambientais? }\end{array}$ & A & & \\
\hline 39 & $\begin{array}{l}\text { A empresa possui passivos ambientais, relativos a empréstimos e } \\
\text { financiamentos de investimento na gestão ambiental? }\end{array}$ & & $\mathrm{D}$ & \\
\hline 40 & A empresa possui multas e indenizações ambientais? & & A & \\
\hline 41 & A empresa possui salários e encargos de especialistas da área ambiental? & A & & \\
\hline 42 & A empresa possui reservas para contingências de natureza ambientais? & & $\mathrm{D}$ & \\
\hline 43 & A empresa tem auferido receitas relativas a valorização do meio ambiente? & A & & \\
\hline 44 & Os custos de vendas são superiores a receitas? & $\mathrm{D}$ & & \\
\hline 45 & $\begin{array}{l}\text { Existe consumo de recursos para controle, preservação, proteção ambiental e } \\
\text { perda acelerada decorrente da exposição de bens a poluição? }\end{array}$ & $\mathrm{D}$ & & \\
\hline 46 & O lucro bruto tem aumentado no último período? & A & & \\
\hline 47 & A empresa paga honorários de profissionais especializados? & A & & \\
\hline 48 & $\begin{array}{l}\text { A empresa paga taxas, contribuições e demais gastos relacionados com a área } \\
\text { ambiental? }\end{array}$ & A & & \\
\hline 49 & $\begin{array}{l}\text { A empresa pagou multas e indenizações por falhas operacionais, como } \\
\text { infração a legislação ou direito de terceiros? }\end{array}$ & $\mathrm{D}$ & & \\
\hline 50 & $\begin{array}{l}\text { A empresa pagou multas e indenizações por acidentes ambientais, perdas por } \\
\text { exposição de pessoas e bens a poluição? }\end{array}$ & & A & \\
\hline
\end{tabular}

Fonte: Dados da pesquisa e adaptado de Silva (2008)

Apesar de não apresentar passivos ambientais relativos a empréstimos e financiamento de investimento na gestão ambiental, no critério IV foi demonstrado o investimento e o interesse da empresa quanto à questão ambiental.

\subsection{Processo produtivo}

O projeto tem inicio nos núcleos de pesquisa através de estudos e análises de compostos e composições para o desenvolvimento de produtos sustentáveis e ecologicamente corretos. A utilização do "Bloco Verde" para construção de um espaço para pesquisas em uma Universidade Publica Federal seria exemplo no seguimento, além de estar preservando o meio ambiente e estimulando novos estudos ligados a instituição de ensino. 
O processo de produção do "Bloco Verde" se inicia com a coleta dos resíduos, feita pelo município vizinho onde esta situada a sede do projeto, após esta etapa as cascas de ostras e mariscos são estocadas no pátio aberto da empresa (Figura 3).

Figura 3 - Estoque de cascas de ostras e mariscos

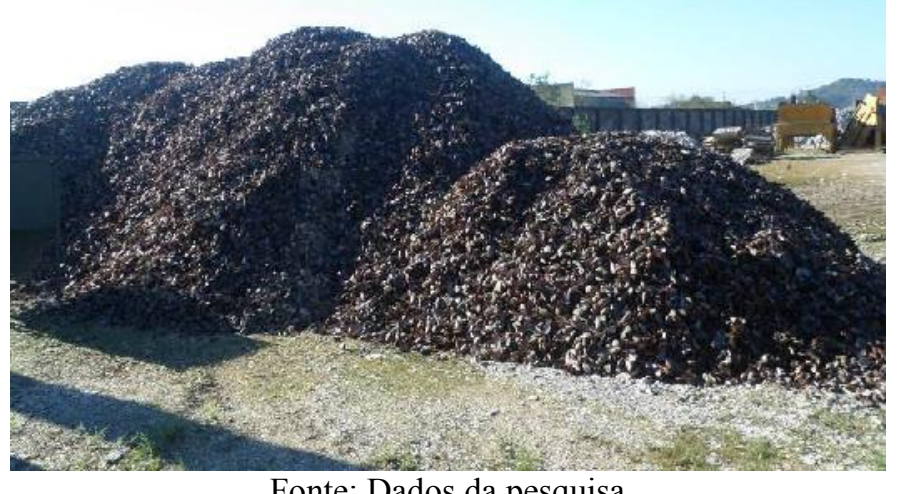

Fonte: Dados da pesquisa

Já depositados no pátio para uso, os resíduos são encaminhados para lavagem e dessalinização (Figura 4). Após a lavagem, toda a água utilizada é reaproveitada, passando por uma miniestação de tratamento (Figura 5), essa água foi coletada da chuva.

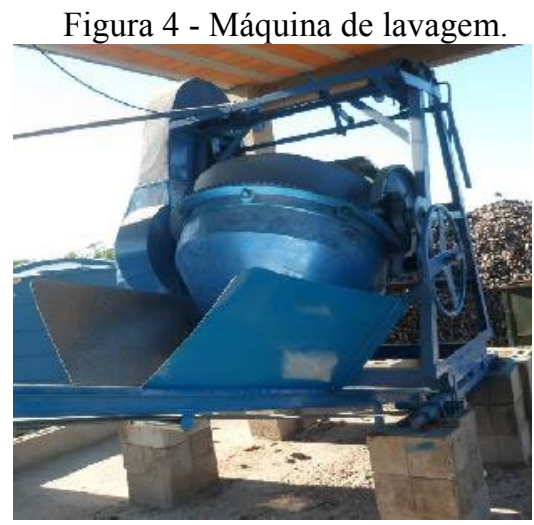

Fonte: Dados da pesquisa
Figura 5 - Estação de tratamento

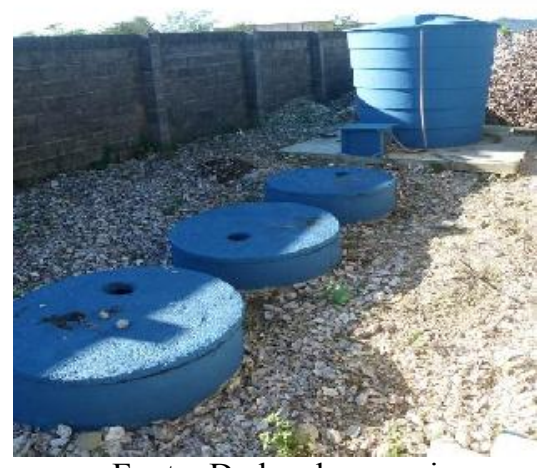

Fonte: Dados da pesquisa

Depois de lavadas as cascas de ostras e mariscos são centrifugadas (Figura 6), logo após passam por dois compartimentos de secagem (Figura 7) e em seguida são trituradas (Figura 8), formando a base para substituição da areia. 
Figura 6 - Centrifugação

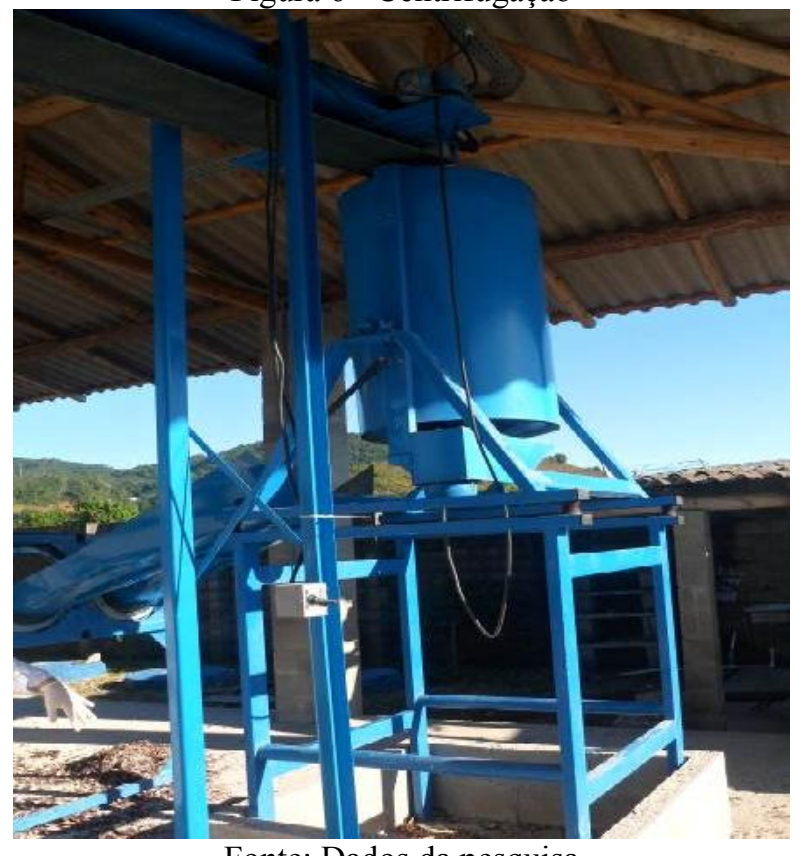

Fonte: Dados da pesquisa

Figura 7 - Secagem

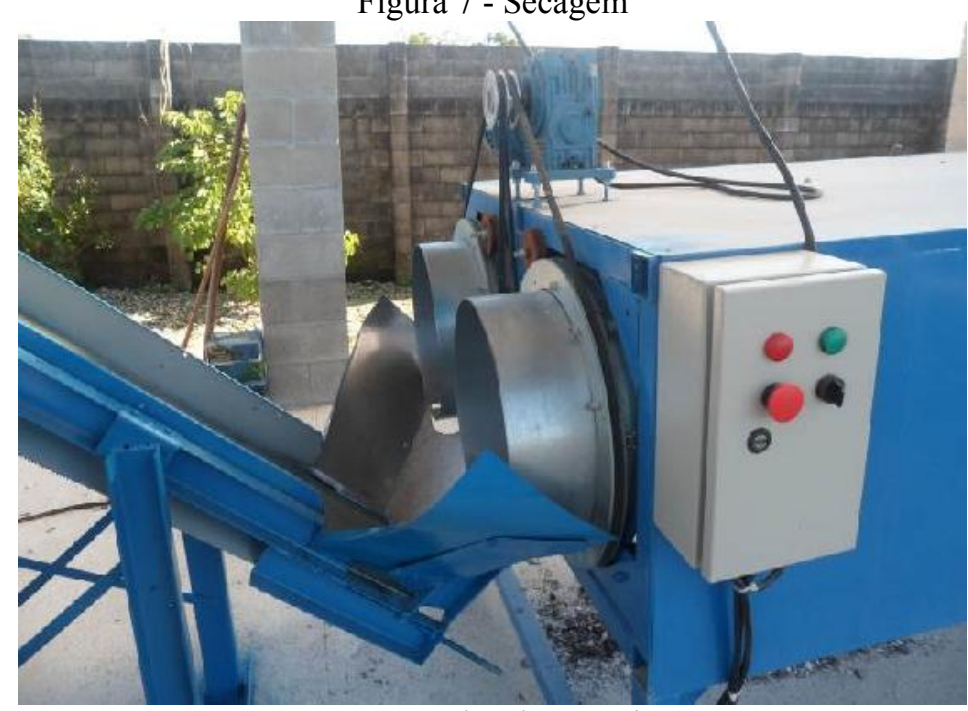

Fonte: Dados da pesquisa

Figura 8 - Trituração

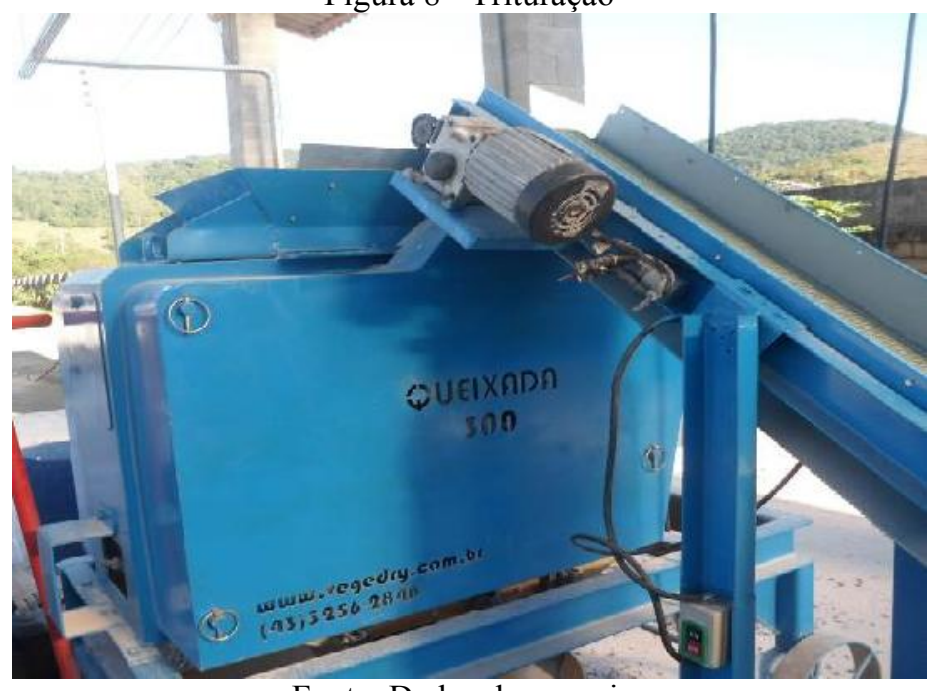

Fonte: Dados da pesquisa 
$\mathrm{Na}$ fase final deste processo, os resíduos já triturados são depositados em tonéis separadamente formando a composição de areia grossa (Figura 9), areia média (Figura 10) e areia fina (Figura 11).

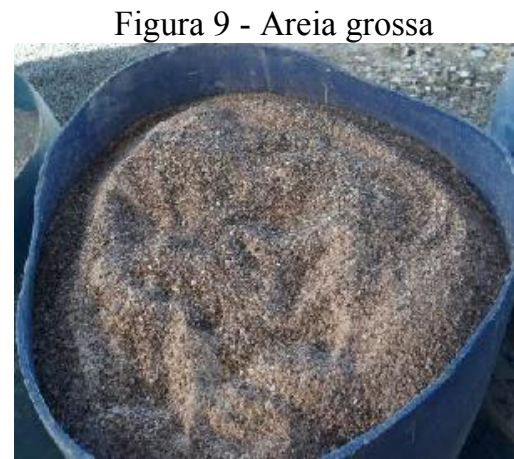

Fonte: Dados da pesquisa
Figura 10 - Areia média

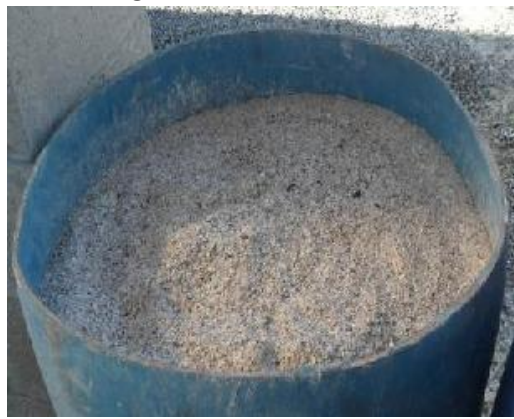

Fonte: Dados da pesquisa
Figura 11 - Areia fina

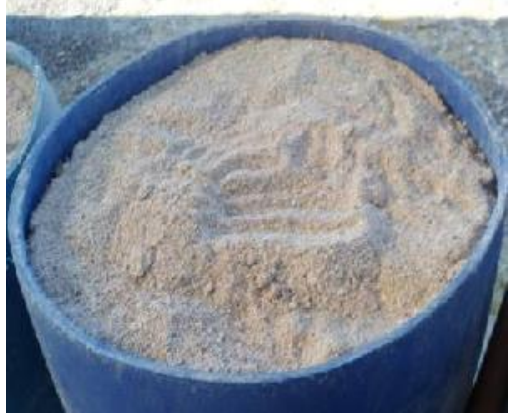

Fonte: Dados da pesquisa

Ao final do processo de transformação dos resíduos em "areia", inicia-se a etapa de produção dos "Blocos Verdes", onde ocorre à mistura dos compostos e o produto final toma sua forma (Figura 12), depois da produção os blocos são embalados e destinados ao mercado consumidor (Figura 13).

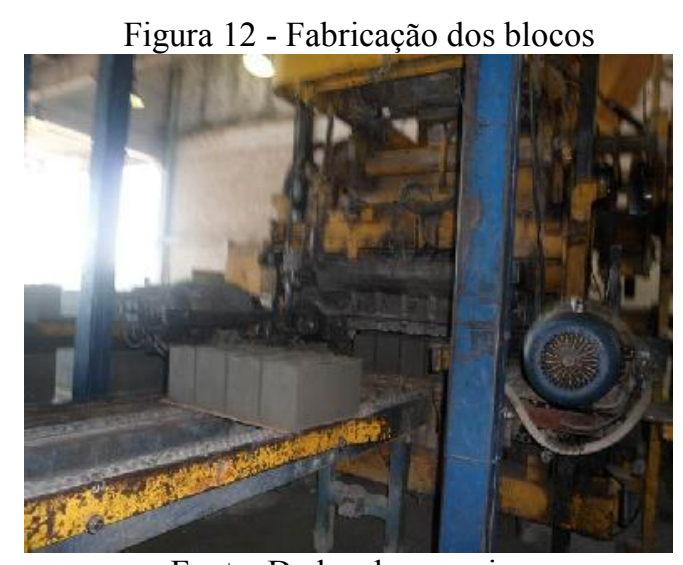

Fonte: Dados da pesquisa

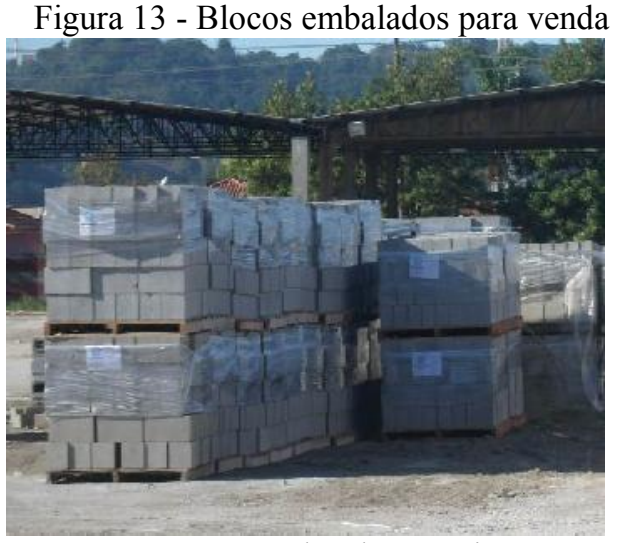

Fonte: Dados da pesquisa

Durante todas as etapas, desde a coleta até o produto final concluído e embalado para venda, se tem o controle e a supervisão dos responsáveis pelo desenvolvimento do projeto "Blocos Verdes", para que tudo ocorra sem danos, tanto ambiental quanto social.

\subsection{Plano resumido de gestão ambiental $-5 \mathrm{~W} 2 \mathrm{H}$}

$\mathrm{O} 5 \mathrm{~W} 2 \mathrm{H}$, o que fazer; por que fazer; quando fazer; onde fazer; quem deve fazer; como se deve fazer; e quanto custa fazer, foi proposto na empresa estudada com a intenção de melhorias na gestão ambiental. Foi aplicado o modelo de gestão no critério com menor grau de sustentabilidade, com uma melhor visualização no Quadro 8. 
Quadro 8 - Desempenho e prioridade de critérios

\begin{tabular}{|c|l|c|c|}
\hline Prioridade & \multicolumn{1}{|c|}{ Critério } & Resultado & Sustentabilidade \\
\hline Segundo & Critério 1: Fornecedores & $83,33 \%$ & Adequado \\
\hline- & Critério 2: Execução do Serviço & $100 \%$ & Adequado \\
\hline- & Critério 3: Responsabilidade Socioambiental & $100 \%$ & Adequado \\
\hline Terceiro & Critério 4: Disponibilidade de Capital & $85,71 \%$ & Adequado \\
\hline Primeiro & Critério 5: Contabilidade e Auditoria Ambiental & $66,67 \%$ & Regular \\
\hline
\end{tabular}

Fonte: Dados da pesquisa

O Quadro 8 - nos proporciona analisar com mais facilidade qual o critério com a menor sustentabilidade e as prioridades, que no caso foi o Critério 5: Contabilidade e Auditoria Ambiental, com isto, aplica-se o 5W2H.

Quadro 9 - Plano resumido de gestão ambiental 5W2H

\begin{tabular}{|c|c|}
\hline & Critério 5: Contabilidade e Auditoria Ambiental \\
\hline What? (O que?) & Aumentar sua participação quanto à proteção, controle e recuperação ambiental. \\
\hline Why? (Por quê?) & Para se tornar mais envolvida com a gestão ambiental. \\
\hline When? (Quando?) & No período de um ano ou exercício. \\
\hline Where? (Onde?) & No departamento financeiro, operacional e gerencial da empresa. \\
\hline Who? (Quem?) & Os pesquisadores e funcionários dos devidos departamentos. \\
\hline How? (Como?) & $\begin{array}{c}\text { Contratação de funcionários ligados a área da gestão ambiental, com incorporação } \\
\text { de passivos ambientais e a constituição de reservas de natureza ambiental. }\end{array}$ \\
\hline How much? (Quanto custa?) & Valores não orçados. \\
\hline
\end{tabular}

Fonte: Dados da pesquisa e adaptado de Pfitscher (2004, p.99)

Para que essa ação proposta seja realizada, o resultado obtido na análise deve circular por dentro desse departamento, para que todos juntos possam se envolver e senilizar-se, e colocar em prática o que foi sugerido, ou até mesmo reaver outros pontos que possam aumentar a sustentabilidade tanto ambiental quanto social da empresa, assim conquistara um melhor reflexo perante a sociedade.

\subsection{Utilização dos "blocos verdes" em universidades públicas federais}

As Universidades Públicas Federais são as responsáveis pelo incentivo ao desenvolvimento sustentável, instruindo seus discentes a aplicar e praticar conceitos sustentáveis, contribuindo com a preservação do meio ambiente e a formação de profissionais qualificados para o desenvolvimento socioambiental.

Tem-se a importância do tema sustentabilidade estar ligada ao cotidiano das instituições de ensino superior traçando novos objetivos para projetos e pesquisas relacionados à responsabilidade ambiental.

O campus de uma Universidade Pública ocupa uma área superior a um milhão de metros

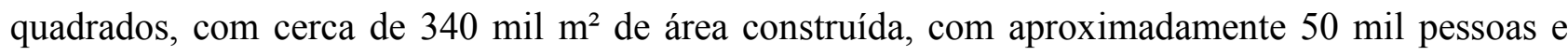
com onze centros de ensino, pesquisa e extensão. Devido a essas proporções torna-se quase que obrigatório à existência de um centro com estrutura sustentável e a disponibilização de novos 
espaços para pesquisas relacionadas à área da construção civil, a fim de desenvolver produtos ecologicamente corretos.

As Universidades Públicas Federais são focadas no ensino, pesquisa e extensão, por essa razão é capazes de realizar projetos em diversas áreas de aplicação, bem como a capitação da água da chuva, a utilização de blocos sustentáveis para construção de centros acadêmicos, a utilização de placas solares para captação de energia elétrica, entre outros que estão ao alcance da Universidade.

Uma das maneiras que as Universidades Públicas Federais têm para colocar o ensino em prática é a criação de grupos ministrados por professores, orientados por profissionais da área, para auxiliar no desenvolvimento prático do estudo realizado.

\section{Conclusões e sugestões para futuros trabalhos}

A crescente preocupação pelo entendimento e interesse das empresas e de Universidades Públicas Federais com o meio ambiente e a sociedade tornou a Responsabilidade Socioambiental um marco importante dentro do mundo empresarial e das Instituições de Ensino Superior.

Este estudo teve por objetivo geral verificar a sustentabilidade e gestão ambiental de uma empresa de blocos verdes pré-fabricados, localizada no munícipio da grande Florianópolis, para a utilização em Universidades Públicas. Para atender a esse objetivo têm-se os seguintes objetivos específicos: verificar a existência de resíduos de cascas de ostras e mariscos para a fabricação dos blocos; analisar a sustentabilidade parcial por critérios na empresa estudada e propor um modelo resumido de gestão ambiental $5 \mathrm{~W} 2 \mathrm{H}$.

A problemática desta pesquisa fica resumida na seguinte questão problema: como se encontra a sustentabilidade ambiental de uma empresa de "blocos verdes pré-fabricados" com a utilização de cascas de mariscos e ostras para utilização em Universidades Públicas Federais?

No processo produtivo Figura 5, relata-se a presença desses resíduos para a fabricação dos blocos, assim comprovado no critério 2 - Execução do Serviço, que a empresa é altamente sustentável, pois apresentou um índice de sustentabilidade de 100\%. Na análise da sustentabilidade parcial por critérios, foi evidenciado que no critério 3 - Responsabilidade Socioambiental, a empresa obteve um nível de sustentabilidade adequada, com 100\%. Já no critério 1 - Fornecedor apesar de ser classificada com nível adequado de sustentabilidade a empresa alcançou 83,33\%, devido seus fornecedores serem monopolistas no mercado. Quanto ao Critério 4 - Disponibilidade de Capital manteve a classificação adequada de sustentabilidade, como apresentado nos outros critérios, porém apresentou $85,71 \%$ de resultado, por pagar multas e indenizações por falhas operacionais, como infração a legislação ou direito de terceiros. 
O critério 5 - Controladoria a auditoria ambiental apresentou o menor índice $(66,67 \%)$, pode este ser aumentado com uma revisão nesta parte da empresa e seguir as sugestões de melhoria contínua, desta forma alcançaria o parâmetro adequado de sustentabilidade.

Com base nos resultados da lista de verificação, pode-se observar que a empresa é focada na sua sustentabilidade, no controle e preservação ambiental, por isto seu índice geral de sustentabilidade global foi caracterizado como adequado, apresentando um percentual de $82 \%$, ou seja, uma alta valorização ambiental para uma empresa envolvida com a construção civil.

Como não na pesquisa não foi constatado a existência de Universidades Públicas Federais com estruturas sustentáveis, a utilização de "Blocos Verdes" para construção de um espaço para pesquisas em uma Universidade Publica Federal seria exemplo no seguimento, além de estar preservando o meio ambiente e estimulando novos estudos ligados a instituição de ensino, pois as práticas sustentáveis devem ser presenciadas no dia a dia.

Para futuros trabalhos, sugere-se aplicar uma nova lista na empresa e comparar com a lista aplicada neste trabalho, para observar o avanço em seus projetos ambientais. Também seria interessante a realização de um estudo nas Universidades Públicas Federais, para saber se passaram a utilizar "blocos verdes" e se incentivam os núcleos de pesquisa a desenvolverem novos projetos relacionados à utilização de materiais ecológicos na construção civil.

\begin{abstract}
This study aims to verify the sustainability and environmental management of a company of prefabricated green blocks, located in the municipality of Florianópolis, for use in Federal Public Universities. To meet this goal have the following specific objectives to verify the existence of waste oyster shells and other seafood for the manufacture of the blocks; analyze the partial sustainability criteria for the studied company and propose a summarized environmental management 5W2H model. The methodology used was descriptive and exploratory character; on the technical procedures considered case study "in situ" and documentary. Through the check list can be seen that the overall sustainability is $82 \%$ considering appropriate. Have criterion 5 Accounting Environmental Audit stood out as the most deficient, with a sustainability index of $66.67 \%$ rated as fair. Because there is no commitment from the company related to the protection, control and environmental restoration, despite having a technological breakthrough in the use of waste for the manufacture of mariculture and eco-paving blocks. Regarding the use of the blocks in Federal Public Universities, their presence was not observed, but are responsible for promoting sustainable development, as it has the function of forming citizens trained for environmental development.
\end{abstract}

Key-words: environmental sustainability; company prefab green blocks; federal public universities.

\title{
Referências
}

ANDREOLI, C.V. Gestão Ambiental. ln: FAE Centro Universitário. Coleção Gestão Empresarial. Curitiba, 2009. p. 66. Disponível em: <http://www.fae.edu/publicacoes/pdf/empresarial/6.pdf/>. Acesso em: 03 de julho de 2010. 
CARDOSO, J.A.; PFITSCHER, E. D. Sustentabilidade Ambiental: Estudo em uma Indústria e Comércio de Artigos Esportivos. In: $4^{\circ}$ Congresso UFSC de Controladoria e Finanças, 2011, Florianópolis. Anais... $4^{\circ}$ Congresso UFSC de Controladoria e Finanças, 2011.

CLARO, P. B. O. ; CLARO, P. D. ; AMÂNCIO, R. Entendendo o conceito de sustentabilidade nas organizações. R. Adm. , São Paulo, v.43, n.4, p.289-300, out./nov./dez. 2008.

DRUNN, K. C.; GARCIA, H. M. UNIC, F. P. Desenvolvimento sustentável e gestão ambiental nas organizações. Revista científica eletrônica de ciências sociais aplicadas da EDUVALE. Publicação científica da Faculdade de Ciências Sociais aplicadas do Vale de São Lourenço-Jaciara/MT. Ano IV, Número 06, novembro de 2011 Periodicidade Semestral- - ISSN 1806-6283.

FREITAS, C. L; avaliação de sustentabilidade em instituições públicas federais de ensino superior (ifes): proposição de um modelo baseado em sistemas gerenciais de avaliação e evidenciação socioambiental. $2004.204 \mathrm{f}$. Dissertação em pós-graduação em contabilidade, universidade federal de santa catarina, florianópolis, 2013.

FREITAS, C. L; et al. Gestão socioambiental e sustentabilidade em instituições de ensino superior: Uma proposta de seleção de portfólio bibliográfico. Revista de Gestão \& Sustentabilidade Ambiental, v. 1, n.2, p. 36-54, 2012 b.

FREITAS, C. L. et al. Missão Institucional: Análise nas Instituições Federais de Ensino Superior (IFES). In: $4^{\circ}$ Congresso UFSC de Controladoria e Finanças, 2011, Florianópolis. Anais do $4^{\circ}$ Congresso UFSC de Iniciação Científica em Contabilidade. Florianópolis: UFSC, 2011. Disponível em:

http://dvl.ccn.ufsc.br/congresso/anais/4CCF/20101216172348.pdf acesso em: 01/04/2014.

GIL, A. C. Como Elaborar Projetos de Pesquisa. 4. ed. São Paulo: Atlas, 2002.

LERÍPIO, A. A. G. Um método de gerenciamento de aspectos e impactos ambientais. 2001. Tese (Doutorado em Engenharia de Produção) - Universidade Federal de Santa Catarina, Florianópolis, 2001.

LIMONGI, B.; SOARES, S. V.; FREITAS, C. L. Análise de confiabilidade do SICOGEA - sistema contábil gerencial e ambiental. Revista catarinense da Ciência Contábil. Revista editada pelo Conselho Federal de Santa Catarina- Ano 12- no 35 - abr./jul. 2013

LUIZ, L. C.; et al . Agenda Ambiental na Administração Pública (A3P) e práticas de sustentabilidade: Um estudo aplicado em um Instituto Federal de Educação, Ciência e Tecnologia (IFECT). In: encontro nacional de gestão empresarial e meio ambiente, 13, 2011, São Paulo. Anais... São Paulo: FGV, EAESP/ USP, FEA, 2011.

MORESI, E. Metodologia da Pesquisa. Pró-Reitoria de Pós-Graduação. Programa de Pós-Graduação Stricto Sensu em Gestão do Conhecimento e Tecnologia da Informação. Brasília: Universidade Católica de Brasília, 2003.

PAMPlONA; PFITSCHER, E. D. ; UHLMANN, V. O. Gestão e Contabilidade Ambiental: Estudo de Caso em Instituição Hospitalar. In: XI ENGEMA, 2009, Fortaleza.

PFITSCHER, E.D. Gestão e sustentabilidade através da contabilidade e controladoria ambiental: estudo de caso na cadeia produtiva de arroz ecológico. 2004. 252 f. Tese (Doutorado em Engenharia de Produção) - Programa de Pós Graduação em Engenharia de Produção, Universidade Federal de Santa Catarina, Florianópolis, 2004. Disponível em: http://www.nemac.ufsc.br/visualizar/teseelisete.pdf - Acesso em 01/04/2014.

PFITSCHER, E. D. Contabilidade e Responsabilidade Social - Florianópolis: Departamento de Ciências Contábeis/UFSC, 2009.

SANTOS, A. P.; CERQUEIRA, E. A. Ensino superior: trajetória histórica e políticas recentes. In: IX Congresso Internacional sobre Gestão Universitária na América do Sul, Florianópolis, Brasil, 2009 Disponível em: https://repositorio.ufsc.br/bitstream/handle/123456789/35836/Ensino\%20Superior\%20trajetoria\%20historica $\% 20 \mathrm{e} \% 20$ politicas\%20recentes.pdf?sequence=1 acesso em: 01/04/2014.

SILVA, C. B. A Responsabilidade Sócio-Ambiental Analisada em uma Rede de Supermercados com Auxílio do SICOGEA. Trabalho de Conclusão de Curso. (Graduação em Ciências Contábeis) - Universidade Federal de Santa Catarina. Orientador: Elisete Dahmer Pfitscher. Florianópolis. 2008. 
SOUZA, V. S. F.; DREHER, M. T.; AMAL, M. A influência da responsabilidade sócio-ambiental no processo de internacionalização: o caso da Electro Aço Altona. Revista de ciências da administração, v. 9, n. 19, p. 103-126, set./dez. 2007.

TAUCHEN, J. ; BRANDLI L. L. A gestão ambiental em instituições de ensino superior: modelo para implantação em campus universitário. Revista Gestão e Produção, v.13, n.3, p. 503-515, setembro - dezembro, 2006.

TACHIZAWA, T. Gestão Ambiental e Responsabilidade Social Corporativa. São Paulo: Atlas, 2004.

TINOCO, E. P.; ROBLES, L. T. A contabilidade da gestão ambiental e sua dimensão para a transparência empresarial: estudo de caso de quatro empresas brasileiras com atuação global. Revista de Administração Pública - RAP, v. 40, núm. 6, Novembro - Dezembro, 2006, pp. 1077-1096. Disponível em: <http://www.scielo.br/pdf/rap/v40n6/08.pdf>. Acesso em: 01 de abril de 2014.

VARGAS, A. B.; PFITSCHER, E. D.; RICHARTZ, F.; KRUGER, L. M.; L. Análise do sistema de gestão ambiental em uma empresa de cosméticos por meio da utilização do SICOGEA - Sistema Contábil Gerencial Ambiental.

Enciclopédia Biosfera, v. 6, p. 15-29, 2010.

BLOCAUS. Disponível em: <http://www.blocaus.com.br/index.php>. Acesso em: 04 de julho de 2012.

BLOCO VERDE. Disponível em: <www.blocoverde.com.br/>. Acesso em: 04 de julho de 2012.

\section{Dados dos autores}

Nome completo: Morgana Mendes Nunes

Filiação institucional: Universidade Federal de Santa Catarina - UFSC

Departamento: Ciências Contábeis

Função ou cargo ocupado: Aluna graduanda

Endereço completo para correspondência: Br 101, Km 250 - Sorocaba - Paulo Lopes/ SC - Brasil CEP: 88490-000.

e-mail: morgana_pl@hotmail.com

Nome completo: Elisete Dahmer Pfitscher

Filiação institucional: Universidade Federal de Santa Catarina - UFSC

Departamento: Ciências Contábeis

Função ou cargo ocupado: Professora Doutora no Programa de Pós-Graduação em Contabilidade.

Endereço completo para correspondência: Rua Mário Cândido Da Silva, Nº 46. Casa. - Bairro Itaguaçu- Florianópolis/SC - CEP: 88.085-475

Fone: 48- 8817-2019 Fax: 48-3721-6620

e-mail: elisete.dahmer@ufsc.br

\section{Submetido em: 11/08/2014}

Aceito em: 17/12/2014 